\title{
Manifestation of characters' status, identity and mobility in Film: A comparative analysis of Sin Nombre, Biutiful, and Parasite
}

\author{
Haley Kathryn Richardson*1 ${ }^{*}$ Abida Bano ${ }^{2}$
}

1. Department of International Studies, University of North Carolina Wilmington, Wilmington, North Carolina, United States.

2. Institute of Peace and Conflict Studies, Faculty of Social Sciences, University of Peshawar, Peshawar, Pakistan.

*Corresponding Author Email: hkr9668@uncw.edu

\begin{abstract}
The scholarly inquiry of film studies focuses on studying multiple aspects of a film by using aesthetic, historical, and critical approaches. A film can amplify suppressed voices of people often overlooked in the margins of society, humanize them, and bring their experiences to the fore. Directors employ various cinematography methods overtly or symbolically to highlight their globalization experiences. A prominent mechanism featured in the cinematic expression of the impacts of globalization - most notably in the films observed for the sake of this paper-is that of 'place.' This paper critically analyses three selected films in which locations and motions are used to connote crucial aspects of the character's identification - status, identity, and mobility. The cinematic spaces encountered in Sin Nombre, Biutiful, and Parasite are pivotal in connoting characters' socioeconomic status, identity, and opportunities for mobility through the symbolic application of movement and setting.
\end{abstract}

\section{Article History}

Received:

June 26, 2021

Revised:

August 29, 2021

Accepted:

September 26, 2021

Published:

December 31, 2021

Keywords: globalization, film studies, character in film, identity in film, socioeconomic status, mise-en-scène, identity, character, social inequity.

\section{How to Cite:}

Richardson, H. K., \& Bano, A. (2021). Manifestation of characters' status, identity and mobility in Film: A comparative analysis of Sin Nombre, Biutiful, and Parasite. Liberal Arts and Social Sciences International Journal (LASSIJ), 5(2), 264-272. https://doi.org/10.47264/idea.lassij/5.2.18

\section{Publisher's Note:}

IDEA PUBLISHERS (IDEA Publications Group) stands neutral with regard to the jurisdictional claims in the published maps and the institutional affiliations.

Copyright: () 2021 The Author(s), published by IDEA PUBLISHERS (IDEA Publications Group).

Licensing: This is an Open Access article published under the Creative Commons AttributionNonCommercial 4.0 International License (http://creativecommons.org/licenses/by-nc/4.0/) 


\section{Introduction}

The scholarly inquiry of film studies focuses on studying the multiple aspects of a film by using aesthetic, historical, and critical approaches of the research. The spread of globalization in the non-Western countries can facilitate an opportunity and success or may complicate the lives of the lower-class members of the society. The differences in government, societal construction, and cultural customs are among the issues which are equally as likely to be helped as hindered by the effects of globalization. The increased international influence tends to overlook the seemingly invisible people of a society, and the lack of resources bars them from the opportunities afforded to those fortunate enough to possess the means to take advantage. A film can amplify the suppressed voices of the people often overlooked in the margins of society, humanize them, and bring their experiences to the fore. Directors employ various cinematography methods either overtly or symbolically to bring out the complications arising from their globalized experience.

The globalization is a contested phenomenon, which on the one hand, has offered opportunities for economic growth and more economic connectedness; but has enhanced suspicions about the economic distribution between and within underdeveloped states (Lee \& Vivarelli, 2006). The optimists of globalization claim that it has offered opportunities to developing societies to alleviate poverty. However, the pessimists argue that it has seemingly complicated the lives of the lower-class members of society in developing countries by widening the gap between various economic classes. In a scenario of cutthroat competition, it has widened the gap between the rich and the poor, wherein the increased international influence often overlooks the seemingly invisible members of the society who are denied opportunities due to lack of access to resources.

Globalization can bring about a more considerable disparity between poor and affluent members of society and exploitation in the search for cheap labour sources. While there are many benefits to globalization - increased access to and use of technology, an abundance of innovation, exposure to various cultures, lower product costs, and higher standards of living worldwide - there are also consequences and underlying disparities that allow for these perks. Bardhan (2006), in his article; Does globalization help or hurt the world's poor? Overview/globalization and poverty discusses how the changes caused by globalization "have caused many hardships for the poor in developing countries but have also created opportunities that some nations utilize, and others do not, largely depending on their domestic political and economic institutions."

The films Biutiful, Parasite, and Sin Nombre, display unique cultural scenarios from a range of countries - Spain, South Korea, and Mexico. Despite the geographical diversity, there exists a common theme in each film, offering insight into the impacts of globalization as reflected in the experiences of underprivileged members of each society. The depiction of characters in Biutiful, Parasite, and Sin Nombre demonstrates the largely homogenous nature and inevitable victimization of a society's lower-class members due to a rapidly expanding global network. This research paper explores the setting to reflect the character progress through movement, landscape, and depiction of the place symbolic of character experience. The identity, class status, and mobility — or lack thereof - of characters in their respective films are expressed using cinematic space. 


\section{Theory and methods}

This paper critically analyses three selected films (Sin Nombre, Biutiful, and Parasite) to argue that places and motion are critical to represent the characters' status and identity in film in a particular context. The three selected films are from diverse contexts of Spain, Mexico, and South Korea, respectively. These films have been produced in 2009, 2010, and 2019 respectively, covering a decade that invariably showcases the struggles of lower socioeconomic classes in society. Despite the context's diversity, all three films show stark similarities in treating the characters while presenting their socioeconomic status and identities in this globalization era. All three films show the fateful struggle of main characters to improve their living conditions in the face of severe adversity and social inequality.

The cases selection (films) is based on appropriateness, which aims to show globalization's workings on the various social classes and their response to it. Several aspects of the films are comparable and resonate with one another. It is important to note that film studies have evolved using various research methods to analyse the crucial aspects of the film. Analysing films hinges on transdisciplinarity and borrows research techniques from social sciences such as thematic and content analysis. The paper examines the key elements of place, motion, set of the film, use of various articles, and shapes to contend that all these elements present and represent the phenomenon of globalization through the characters' status, identity, and struggle with social inequality.

\subsection{Mise-en-scène}

There is a human tendency to identify oneself with a location of origin. Geographical location can represent identity as it connects the individual to a tangible place saturated in cultural association, familial ties, ethnic customs/traditions-all of which can generate powerful positive or negative emotions. According to authors Ujang and Zakariya (2015) in their article, The notion of place, place meaning, and identity in urban regeneration, "the places play a vital role in developing and maintaining the self-identity and the group identity of the people" (Ujang \& Zakariya, 2015, p. 712). In his article, The psychology of social class: How socioeconomic status impacts thought, feelings and behaviour, Manstead (2018) argue that the socioeconomic status surrounding a person's early development impacts their personal and the social identities, which, in turn, influences the social behaviours and the way the people think and react.

The significance of a place is not exclusive to a geographical location but rather is intensified and ultimately defined by its inhabitants. The interactions between the people of a specific space assign meaning and connection to the place and the individuals who dwell within it. There is mutual dependability between the people and place, which is "distinguished by its people, markets, governments, and institutions, as much as it is by its physical landscape and the natural resources, transportation systems (including streets and roads), buildings, and boundaries," all of which contribute to it becoming "an ensemble concept" (National Research Council, 2002, p. 55).

In the film, mise-en-scène 'refers to everything the camera films,' emphasizing physical direction and the arrangement of people and objects in a space to encapsulate a story (Klein, 2020 , p. In the film, mise-en-scène 'refers to everything the camera films,' emphasizing 
physical direction and the arrangement of people and objects in a space to encapsulate a story (Klein, 2020, p. 145). This, consequently, can be reflected onto a character to illustrate emotions, class status, relationships, and other defining and meaningful characteristics. The film setting provides the physical space where different characters interact within a larger established geographical position. The concept of 'place' in storytelling can denote a character's identity, socioeconomic status, and opportunity for mobility - both symbolically and literally. The spaces occupied in the films Sin Nombre, Biutiful, and Parasite are pivotal in connoting the character's identity and socioeconomic status.

\section{Analysis and discussion}

\subsection{Social identification through using locations, shapes, objects, and motion}

Sin Nombre displays setting to convey the various factors that construct characters' identity and societal status. Gang residences display a juxtaposition of belonging and disconnect, as community spaces emphasize familial-like bonds between members while also cultivating aspects of unease and fear for those who do not entirely conform. The communal space is home to many antithetical activities - from violence in killing and sexual abuse to the shared meals and the family life. Graffiti on the walls of architectural structures is like the bodies of gang members, abundant with tattoos worn as symbols of pride and pledges of loyalty. The layout of the MS-13 gang residence seemed maze-like, with the camera following the Smiley's tour of the building. Each room is a cacophony of the activity demonstrating features of the gang life such as tattooing, drugs, and money being sorted, guns, and sexual activity until the Casper and Smiley comes out into the courtyard-like area where a rival gang member is held awaiting the execution.

Casper's main character is shown at the film's start amidst a grungy yet ethereal setting alongside his girlfriend, Martha. Sunlight pours over them, and genuine affection takes precedence over all else, establishing humanity but foreshadowing the violent events to come. A large portion of the film takes place during train travel and offers varied landscapes representative of the range of emotions endured by the characters partaking in their journeys. The scenes at various depots where the train stops along the journey demonstrate the risks immigrants take in their efforts to escape their prior circumstances. They gather in poor weather conditions, surrounded by trash and graffitied walls. Though home life was dangerous enough to illicit escape, it was familiar. This is illustrated in great contrast to the ever-changing and equally dangerous risks involved in the immigration experience; all made worthwhile when an idealistic, bright version of the United States is waiting at the end.

In the second film of interest, Biutiful, the city of Barcelona is presented contradictory to the sugar-coated projection of idyllic cities most often prevalent in the film. This is a prominent element of Benjamin Fraser's article, A 'Biutiful' City: Alejandro González Iñárritu's Filmic critique of the 'Barcelona Model,' in which he asserts that the film displays "not a dystopic future Barcelona but the dark underbelly of the Barcelona that already exists" (Fraser, 2012, p. 20). However, when considering the functions of mise-en-scène, Fraser's argument is abundantly valid. It would be inauthentic to character experience if the setting did not reflect the hardships and difficulties faced by the minority groups within a city often shown as a bright, sunny vacation destination. The Barcelona is gloomy and dark throughout the majority of Biutiful. The crowds of people suggest an entrapment of mobility beyond one's current social 
class as well as an inability to escape from the confines of the societal categorization. Whether it is the immigrant workers clustered together in the warehouse space which functions both as a dwelling and the place of work, the intermingling of multiple classes as labourers sell their wares on the street, or an indulgent moment at a nightclub when the main character Uxbal is surrounded by temptation, lingering claustrophobia is imparted upon the viewer as they share in the characters' experiences.

Uxbal's apartment is old and lived-in, with worn furniture and dilapidated yet comfortable decor - the cluster of material belongings and absence of pristine cleanliness lacks overlysanitary discomfort. The Chinese immigrant workers who live in a large, cold factory basement sleep in communal clusters without privacy or personal space. For many of the inhabitants, the conditions of a space that doubles for life and work purposes connotes a certain monotony and coldness projected through the use of grey colour and lack of sunlight. Fraser mentions the utilization of the colour blue to reflect emotion and symbolic significance in connection to the location, stating the colour "acquires a special resonance, heightening the film's sympathetic portrayal of its marginalized and even tragic immigrant characters," as well as its historical significance "for deep sadness and melancholy," and Barcelona's "proximity to the Mediterranean Sea" (Fraser, 2012, p. 27).

\subsection{Place (spaces/locations) - a way to show characters socioeconomic conditions}

The contrast between places of residence in Parasite represents stark differences in living conditions between the socioeconomic classes of the Kim and Park families. In the article, Parasite onward: A deep fall without depth, author Koh (2020) holds that the film "revolves around the verticality of architectural structures as profoundly symbolic of the levels in which the human figures reside and for the stratification of the cultural context surrounding them," eventually taking shape with such depth as to "represent the people who live within specific and dramatically different circumstances" (Koh, 2020, p. 932). The semi-basement home of the Kims suggests a possibility, however slight, of hope beyond the entrapment of the class status. Their entrepreneurial spirit and the hard work initially seem to improve their conditions, but the success never fully materializes. They must work tirelessly to achieve even the most minor victories.

The Kim family lives in inconvenience, clustered together in their semi-basement dwelling with a window that allows for little of its intended functional purpose as it does not afford much sunlight in their dimly lit space. Their only view outside is the sight of the drunk people urinating. Fumigators spray chemicals for stink bugs into the opened windows of the Kim family's home, suggesting the metaphorical significance of bugs reflecting the family's status. Their bathroom doubles as an office - the only location in which an internet connection is accessible. The architectural structures surrounding their home are made up of grey hues, and life is only present in the form of humans, as even the weeds struggle to rise between the cracks of the concrete.

The Kim family's dwelling contrasts to the display of the Park residence, which is a sterile environment devoid of imperfections. Their environment suggests security, a strictly scheduled lifestyle, and reflective of that safety, leaving them detached. Their wall-to-wall window fills the home with sunlight and displays a meadow of lush, green grass surrounded by trees and a view of the sky unencumbered by tall grey buildings. Bright and modern with a labyrinth of 
staircases which the Parks are predominantly shown ascending. At the surface level, everything seems 'perfect' in the Park family's home, but there is a hidden secret of even greater poverty than that of the Kim's, which looms below the surface of false flawlessness. The total basementdwelling underneath the Park residence has no windows allowing sunlight but complete darkness except for the harsh fluorescent light-projecting qualities of complete poverty, entrapment, and an ultimate lack of human agency.

\subsection{Lighting and colours use}

The film directors often utilize some supportive elements such as lighting and décor to elaborate upon the concepts and convey the meaning of the form alluded to in the set picture. The careful use of lighting in the Parasite, Bong Joon-ho, augments the mood of both the landscape and the characters within, even the foreshadowing events. In the house of the Kims, the lighting is fluorescent with a yellow-green hue. The unclear nature of the artificial lighting seems to typify the putrid 'smell' alluded to throughout the film in reference from the upperclass Parks to the lower-class Kims - providing a tangibility to the sense of smell which is unavailable in all other ways to viewers of cinema. A critical feature of the film occurs when rain showers disrupt the Park family's camping plans - a minor inconvenience in comparison to the devastating impacts of flooding in the Kim family's neighbourhoods, destroying what little they own. While the Parks relish in the romantic atmosphere provided by the rainstorm, the Kims return to find their home submerged in an overflow of sewage as they desperately rush to save what they can.

\subsection{Effects of globalization on the impoverished}

Films can highlight the disparities between socioeconomic classes and amplify the voices of those typically unheard or simply underrepresented. Globalization has facilitated an inherently faulty system in which lower classes, due to their lack of access to economic resources and opportunities to reskill, are often left with no choice but to accept what they are offered by employers in whom it has been systematically engrained to pay the bare minimum and reap maximum profit. Due to the structure of such societies, these impoverished members have little recourse to defend themselves both on a social and governmental level. For example, in the case of large-scale production factories prevalent in the Asian countries, "wages are low by world standards but much higher than [workers] would earn in alternative occupations" (Bardhan, 2006). While this is convenient and one of the only methods of survival in the shortterm, this pays structure perpetuates the issue of worker exploitation, creating devastating longterm effects.

In cinema, the utilization of camera angles and directed movements translate characters' experiences and difficulty in rising above a pre-ordained social status. The technique of directive movement is prevalent in Bong Joon-ho's Parasite and Cary Joji Fukunaga's Sin Nombre. In Parasite, movement is especially prevalent when the lower-class Kim family is featured. The Kims are victims of a system stacked against them, nevertheless ambitious to rise from their basement-dwelling as they con their way into employment at the hilltop residence of the Park family. When traveling from their home, members of the Kim family are often shown trudging uphill, struggling to rise from their origin, and subsequently forced to retreat to the basement at the end of the day. Stairs are a prominent feature of the film, as the Park family are almost exclusively shown ascending. In contrast, the Kim family is in a constant 
flux of both traveling upward and downward-reflective of their class status and their circumstances' ever-shifting instability and unpredictability.

Mobility in Sin Nombre is depicted by the train's movement, which simultaneously occupies the space of setting and becomes a character unto itself. Much of the film takes place on top of a train, both providing insight into the immigrant experience and depicting 'forward' motion, both literally and symbolically, as characters aboard move closer to the possibility for the opportunity. The train adopts a character-like quality of its own, with an attitude that stops for nothing - determined to forge on until the destination is reached. The train is oblivious to what occurs on top of it-robbery, attempted rape, murder, and even Sayra's father falling off in an attempt to escape border patrol - and it is an unconventional dwelling for people which further dehumanizes the immigrants, many of whom are background fillers in the more extensive set. The final destination of the United States is idyllic and presented with the impression that all aspects of life will improve once the immigrants cross the finish line. The film's abrupt ending fails to reassure the viewer of the immigrants' fate and whether the depiction of the fantasized end goal was indeed achieved or not.

\section{Conclusion}

The setting in the film sparks opinion and biases in viewers, assigning meaning to and bestowing prejudices upon characters before stories fully unfold. These learned reactions are instinctual, resulting from societal conditioning and exposure - or lack thereof - to various social, economic, and personal conditions on a global scale. Viewers assign meaning and stereotypes to the appearance and setting which surrounds characters in films. Viewers do not approach films with a blank slate nor do they offer an absence of previous experience based upon prior consumption of information from other mediums of entertainment or real-life experiences.

A film is a multi-faceted approach to educating audiences of the political, governmental, and societal forces which push characters to resort to violence, escapism, and a rejection of state rules. Directors rely on the viewers' perceived prejudices and either seek to monopolize upon this conditioning or change opinions by creating multi-dimensional characters who challenge stereotypes. Presenting multi-faceted characters by providing backstory and assigning context to character attitudes can humanize such characters in the pursuit of empathy and understanding - a challenge to social constructs. The film provides varied points of view concerning a single scenario and offers accountability for the circumstances that trap lowerclass characters - those victimized by globalization who lack agency.

By employing the elements of mise-en-scène, the directors cast a light on the inequality resulting from globalization. Though set in various contrasting geographical locations, the three films observed reflect similar struggles across the global sphere. Each society presents a systematic power imbalance. The most accessible form of progression for lower classes is to claim power using violence, dishonesty, and/or complete rejection of the state employing breach of law or complete abandonment of the system, which restricts them from exercising agency through immigration. While place serves to translate certain character traits, it also displays a lack of belonging into the larger society the victimized characters inhabit. For example, the scenes depicted in Biutiful are in sharp contrast to the beauty and idealistic portrayal typically associated with Barcelona. Similarly, in Parasite, the visually unappealing 
presentation of the lower-class Kim family sets it apart disparagingly as the Park family is shown with a glowing aura. Even in Sin Nombre, failure to conform to the norms of society forces them to seek an entirely different place of inhabitants in the search for opportunity, escape, and belonging.

Motion in Biutiful, Parasite, and Sin Nombre - both in the monotony of daily life or in the pursuit of a larger aspiration-is often presented in the context of a character's societal rank and tracks their progress or regress throughout the film. Fast-paced and sweeping camera movements connote the rushed and ever-shifting quality of life for the lower-class members of society when presented on-screen. Often, upward movement is followed with downward to suggest that hope for success in globalized societies can be momentary and fleeting for the lower classes. Even when progressive movement is momentarily obtained, a great struggle precedes it.

The medium of the film utilizes a range of symbolic, metaphorical, and literal techniques to convey the message and story director's desire. In Biutiful, Parasite, and Sin Nombre, there is a strong emphasis on dwellings to reflect character qualities of personality, emotion, class status, and belonging. The place to signify class status can further cement a character's seemingly immovable location on the margins of society. Spaces adopt identities of their own - often reflective of what characters inhabit them both openly display and internally hold, often dampened by oppressive factors of a globalized society. Authors Ujang and Zakariya (2015) assert, "places are dynamic and continue to regenerate as people struggle to adapt to new meanings that might have detached from their culture and identity" (Ujang \& Zakariya, 2015, p. 711). As globalization continues to infiltrate societies around the world, a film can shine a light on the dark places where marginalized people are exploited and suffering to provide those in the upper echelons with the perks of a global economy and diverse society bring about change.

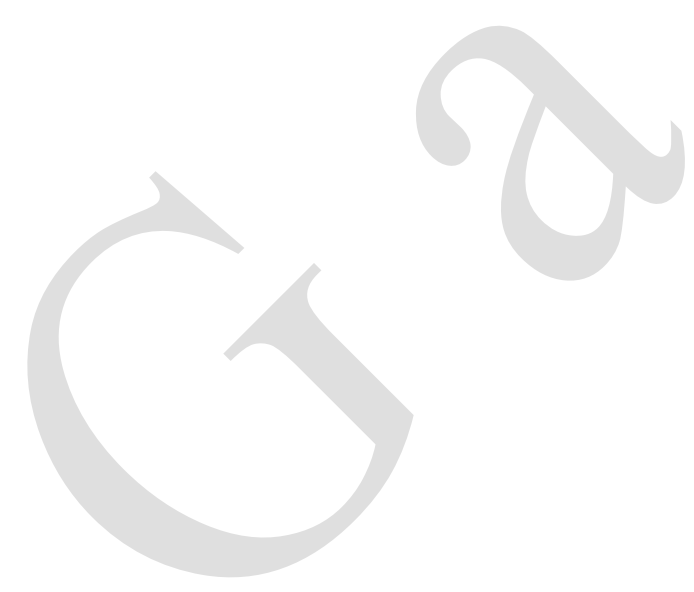




\section{References}

Bardhan, P. (2006). Does globalization help or hurt the world's poor? Scientific American, 294(4), 84-91. https://www.scientificamerican.com/article/doesglobalization-help-o-2006-04/

Biutiful (2011). Directed by Alejandro González Iñárritu, Lions Gate Films.

Fraser, B. (2012). A Biutiful City: Alejandro González Iñárritu's filmic critique of the 'Barcelona Model'. Studies in Hispanic Cinemas (New title: Studies in Spanish \& Latin American Cinemas), 9(1), 19-34. https://doi.org/10.1386/shci.9.1.19_1

Klein, C. (2020). Consumer culture and the black market: Mise-En-Scène. In Cold war cosmopolitanism: Period style in 1950s Korean Cinema ( $1^{\text {st }}$ Ed.) (pp. 144-178), University of California. www.jstor.org/stable/j.ctv1f8851b.12

Koh, H. K. (2020). Parasite onward: A deep fall without depth. Journal of Analytical Psychology, 65(5), 932-936. https://pep-web.org/browse/document/joap.065.0932a

Lee, E., \& Vivarelli, M. (2006). The social impact of globalization in developing $\begin{array}{llll}\text { countries. International Lab. } & \text { Review, 145, }\end{array}$ https://www.econstor.eu/bitstream/10419/33211/1/506211703.pdf

Manstead, A. S. (2018). The psychology of social class: How socioeconomic status impacts thought, feelings, and behaviour. British Journal of Social Psychology, 57(2), 267291. https://doi.org/10.1111/bjso.12251

National Research Council. (2002). Community and quality of life: Data needs for informed decision making. The National Academies Press. https://doi.org/10.17226/10262

Parasite (2019). Directed by Bong Joon Ho, Neon.

Sin Nombre (2009). Directed by Cary Joji Fukunaga, Focus Features.

Ujang, N., \& Zakariya, K. (2015). The notion of place, place meaning, and identity in urban regeneration. Procedia-social and Behavioural Sciences, 170, 709-717. https://doi.org/10.1016/j.sbspro.2015.01.073 